\title{
The history and legacy of the United States Naval Communication Station in Thurso, Scotland
}

\author{
J. B. Gunn \\ Environmental Closure and Demolition Department, \\ Dounreay Site Restoration Limited, UK
}

\begin{abstract}
The United States (US) Navy built a radio station at Forss near Thurso, Scotland, in 1962 to meet a need for improved communication services to US and North Atlantic Treaty Organisation (NATO) forces operating in the North Atlantic and North Sea. The station was fully contained, but most sailors lived in the local community due to limited living quarters. Social integration was a great success with the station's leisure facilities being open to locals and sailors participating in community events. Around 100 sailors married local girls. Many who worked at the station have continued their friendships with colleagues and locals via social media. The station closed in 1992 and the Forss site was abandoned for ten years. $£ 6.5$ million of private and public money was spent in developing it into a modern business and technology park. The park is located near to the Dounreay nuclear establishment and its concept is based on creating a cluster of expertise in the nuclear decommissioning and allied industries, such as oil and gas, renewables and marine. This paper covers the technical and social history of the US Navy's tour-of-duty in Thurso, its legacy and how the defence site was redeveloped for the socio economic benefit of the area.

Keywords: NAVCOMMSTA UK, NAVRADSTA Thurso, US naval radio station, US Navy communications, nuclear decommissioning, Forss, Dounreay.
\end{abstract}

\section{Introduction}

Due to the Cold War, the United States (US) established numerous military bases throughout the world and in 1962 the decision was made to build a naval radio station near the small seaside town of Thurso in Caithness, on the North coast of 
Scotland. The transmitter site was built at Forss, West of Thurso and near to the Dounreay nuclear establishment, the much smaller receiver site at West Murkle, East of Thurso, the unmanned relay station at Latheron in South Caithness and 26 naval housing units in Thurso. The station played a vital part in the communications for the defence of the free world for 30 years, by meeting a need for improved communication services to US and North Atlantic Treaty Organisation (NATO) forces operating in the North Atlantic and North Sea.

The station closed in 1992 and the Forss site stood empty for ten years before being turned into a business and technology park. This paper covers the technical and social history of the US Navy's tour-of-duty in Thurso, its legacy and how the defence site was redeveloped for the socio economic benefit of the area. It concentrates on the main site at Forss and not the other much smaller sites.

\section{Station history}

Construction began in 1962 and the station was formally commissioned as Naval Radio Station (NAVRADSTA) Thurso (fig. 1), on 3 January 1964, with the officer in charge being Lt Commander Francis C Waterloo. The station was originally under the Commanding Officer of the Naval Communication Station (NAVCOMMSTA) Londonderry, Northern Ireland. Thurso changed its status to that of an independent Command on 1st October 1973, with Commander Joseph I Converse Jr, being the station's first Commander. The name was changed to Naval Communication Unit, Thurso, on 1 March 1976 and was redesignated as NAVCOMMSTA United Kingdom (UK), on 1 October 1977, in recognition of its full range of communication services and capabilities.

The mission was to operate, maintain and manage those facilities, equipment and systems necessary to provide requisite communications for the command, control and administration of the naval establishment and defence communications system. The station provided a wide range of voice, telex and satellite services.

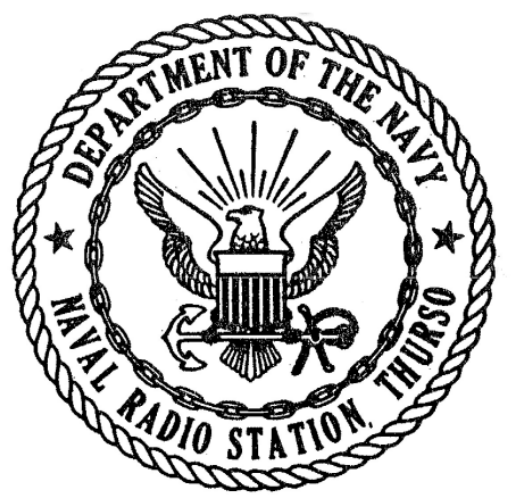

Figure 1: NAVRADSTA Thurso crest. 
The end of the Cold War, modern advances in communications and an economy drive by the US Defence Department, spelled the eventual closure of many US bases throughout the world, including Thurso. The stand-down ceremony took place at the Forss site on 4 November 1992 and was attended by 200 invited guests, including senior officers from the US and UK Royal Navy. The sailors were reluctant to leave and the sombre ceremony was reported in the local press [1]. The last of the personnel left on 17 December 1992 and ownership of the naval houses, emptied facilities and land was transferred to the UK Ministry of Defence (MoD) [2].

\section{Station description}

The site at Forss, (National Grid Reference ND022698) six miles West of Thurso (fig. 2), was the main site with 126 acres of land containing an extensive antennae field and a cluster of 21 buildings, named as follows:

- Transmitter, emergency power, bachelor's enlisted quarters, fuel station;

- Transport, commissary/security, enlisted men's club, bowling alley;

- Quarterdeck/exchange/administration, gymnasium, riggers/utility;

- Supply, public works, pumphouse, disintegrator, medical/dental;

- Flammable goods, moral welfare and recreation store, public works store;

- Fire-fighting training, vehicle store.

The antennae field supported a single $610 \mathrm{ft}(186 \mathrm{~m})$ high guyed lattice mast and sixteen smaller antennae with associated steel wire guys (fig. 3) [3]. There was plenty on offer during leisure time as the Forss site had; two leisure clubs with bars, dart boards, pool tables, slot machines, shuffle boards and dance floor, a skeet shooting range, baseball pitch, gymnasium, sauna, racket ball court, ten pin bowling alley, ceramics workshop with kiln, photographic laboratory, vehicle repair workshop, library and daily movie shows.

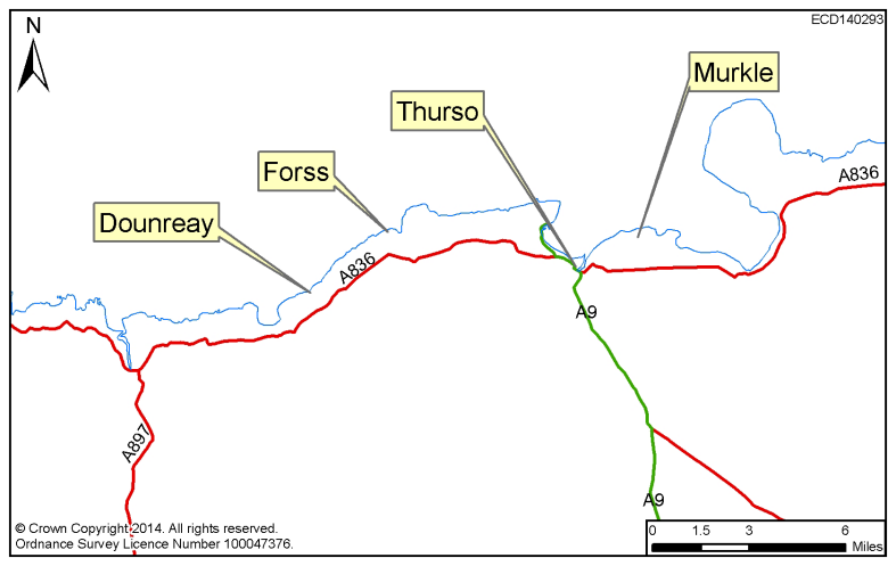

Figure 2: Map showing location of US Navy facilities and Dounreay nuclear site. (Crown copyright 2014.) 


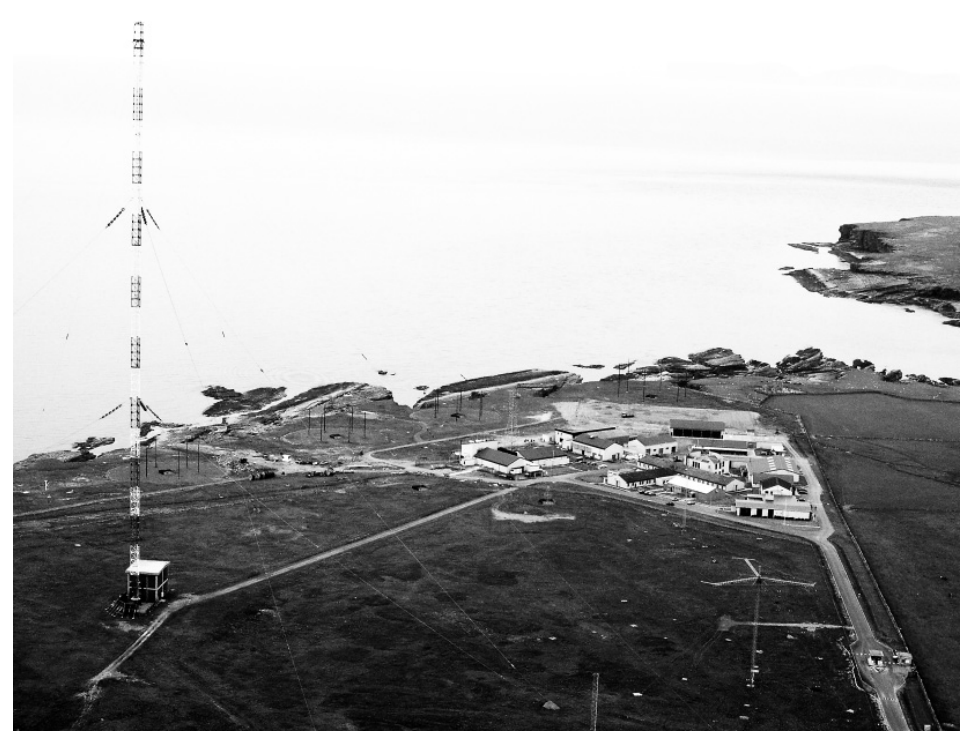

Figure 3: Aerial view of transmitter site at Forss. 1 June 1986. (Copyright: NDA and DSRL.)

The Exchange sold a limited range of US goods and merchandise, while the Commissary had US groceries and drinks. However, sailors and their families bought most of their groceries and goods in the local community [2, 4].

The Command also included a small receiver site at West Murkle, two miles East of Thurso, which had one main building and an antennae field. There was an unmanned relay station at Latheron, 29 miles south of Thurso.

\section{Station organisation}

The organisational structure consisted of three departments; communications, electronics maintenance and support. Support covered administration, public works and supply. Supply consisted of purchasing, payroll, personal property, the galley and the warehouse. Public Works covered site maintenance and had a large contingent of civilian joiners, electricians, masons, riggers and mechanics [2]. There was a Corpsman on site to give emergency medical treatment, but personnel could use the local medical services. The station was built by the US Navy's Construction Battalion widely known as the "Sea Bees" due to the initials CB. The Sea Bees continued to have a small presence due to on-going construction and renovation work.

After 1973, the station had its own Commander supported by seven Officers. The number of personnel varied from 90 to circa 200 sailors and from 40 to 80 civilians. Sailors' wives often worked on the site. A tour-of-duty counted as sea duty with sea pay and consisted of two years for enlisted personnel with dependents or 18 months for single sailors. The station was run like a ship with the 
main administration building being called the Quarterdeck and a change in command taking place under a formal military ceremony. The site had a security fence and a gatehouse with armed guards. The navy personnel wore their standard uniforms and worked with the civilians as one combined team, resulting in a friendly relaxed working atmosphere, despite the military formalities [2].

The main function was ship-to-shore communications with friendly ships, destroyers, aircraft carriers and submarines. The station did not have a spying mission. When a ship came up on designated monitored frequencies, these signals were passed from Murkle to the Forss technical control message centre, where the ship-to-shore interface took place. Morse code was used at first, before communications progressed to teletype/telex and finally satellites with computer terminals. Voice communications using VHF radio was rare [4].

\section{Social aspects}

The site at Forss had all the facilities needed to live on campus, but there were only 15 twin bedroomed living quarters that were reserved for single sailors. The others had the choice of renting one of the 26 naval housing units in Thurso, houses in Castletown that were leased by the navy or renting privately [5]. The Thurso houses were specifically built for the US Navy and the new street was appropriately named John Kennedy Drive. The married sailors brought their families and their possessions with them and so the American presence ran into many hundreds at any one time. The local economy was boosted by around £3M annually, due to rental income, buying goods and services, enjoying sport and leisure activities, wages of civilian workers and facilities contract work.

The US Navy would have expected some social integration issues, however, for the previous eight years the local community had already been involved in a vast social integration challenge. This was due to the sudden "invasion" of over 1,200 workers and their families, who came to work for the United Kingdom Atomic Energy Authority (UKAEA) at the Dounreay nuclear research and development establishment or for Rolls-Royce and Associates at the neighbouring MoD nuclear submarine test site, HMS Vulcan. Thurso became an "atomic boom town" with the population tripling from around 3,000 to 9,000 in only eight years. The town had a new vibrance about it and became quite cosmopolitan. Caithnessians were generally appreciative of what Dounreay brought to the county and embraced the vast number of "Atomics" so that social integration was not an issue. The addition of another few hundred new faces was therefore no big deal and the Americans were openly welcomed, much to their surprise and delight. The children attended local primary schools and most attended Thurso High School rather than travelling to attend a US school in England.

The dances and social events at Forss were often open to civilian guests and they became legendary! The sailors knew how to let their hair down and party and they were a huge hit with the local girls. Around 100 trans-Atlantic marriages took place during the station's 30 year lifetime. A big attraction was the provision of US beers and food, with the likes of Budweiser, Michelob, Kentucky Fried Chicken, French fries, Pringle crisps and roasted peanuts going down particularly 
well with visitors. Today these are all readily available in supermarkets, but back then, they were totally new and novel to North Scotland.

The Commanders actively promoted and encouraged the sailors to participate in local community events to project a positive American presence. The station had a quarterly newsletter, which detailed the latest news of work and social activities [6]. Some of the annual social events were; open day, summer BBQ, US Independence Day, Halloween, Thanksgiving, Santa's Grotto, Christmas party, civilian dinner dance and a navy day ball. Sailors also joined local clubs and organisations such as the Rotary and Round Table and helped organise and participate in, local charity and sports events such as Thurso's Annual Street Fair and NAVCOMMSTA UK golf tournament. Taking part in the traditional Scottish heavyweight events at the Mey Highland Games was a highlight, especially as it was attended by Her Majesty Queen Elizabeth, the Queen Mother, who resided at the nearby Castle of Mey. The Command had the great honour of a visit from Her Majesty in 1983, where she had tea and cakes with US Navy personnel at Forss $[2,4]$.

The influx of Dounreay workers and their families resulted in many new sports being introduced to Caithness, but the US Navy introduced a totally new one, which was a great success. Forss had a ten pin bowling alley (two lanes) and interest was so high with locals that a Caithness bowling league was formed. The sailors were also keen darts players and they joined the local darts league.

There is an ancient stone broch on the site near the sea cliffs. In their free time many sailors helped the University of Glasgow Archaeology Department to excavate the broch and in doing so, discovered two skeletons [7].

Social integration was a great success and the Command often received a special award from The Ambassador of the United States of America in the Court of St James's (London), for “outstanding efforts in furthering cordial community relations in the UK and thereby strengthening the Scottish-American Alliance" [6]. This social success is one of the main reasons why many sailors stationed at Thurso, say that it was their best tour ever. The only downside ever mentioned was the Caithness weather! Every season had a habit of being cold, wet and very windy at times.

This fondness has evolved into the creation of websites and a Facebook page for ex-sailors and locals to keep in touch [8-11]. It is estimated that there were over 2,000 sailors and 150 civilians stationed at Thurso. Sailors were presented with a commemorative plaque at the end of each tour and when the station closed, every civilian worker also received one $[2,4]$. The Command had its own officially registered Scottish tartan and the plaque design incorporated a small swatch of material. The tartan was officially registered in 1985 with the name "U.S. Forces Thurso" [12].

\section{Legacy}

Prior to leaving, the US Navy arranged for a local stone mason to build a $1.8 \mathrm{~m}$ high Caithness stone cairn on the Forss site, near the cliff top (fig. 4). 


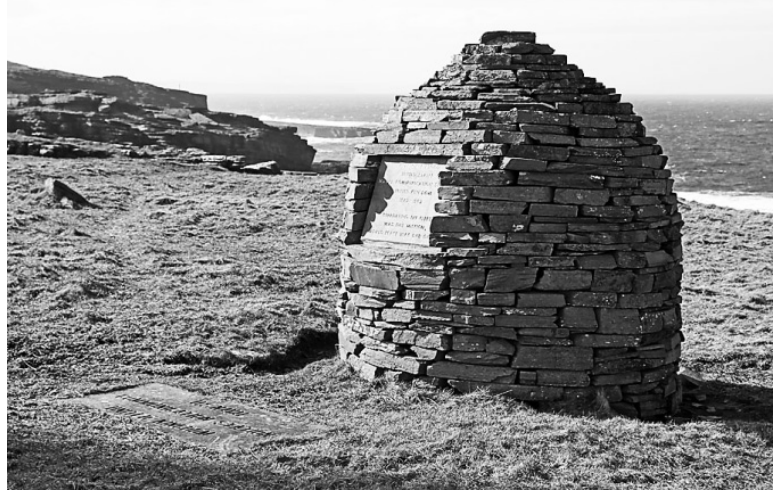

Figure 4: Commemorative stone cairn at Forss site. 13 March 2014.

The cairn's inscription states; "Here once stood United States Naval Communication Station, United Kingdom. 1962-1992. Supporting the fleet was our mission, world peace was our goal." It is reported to contain a time capsule [4].

The sites were stripped of all equipment and furniture, which went for scrap or reused at other stations. However, the ten pin bowling alley was reinstalled in Thurso's cinema and leisure complex for community benefit. The US Navy also set up a trust to fund an annual award for students in computer and telecommunications studies at Thurso College. The Thurso branch of the Royal British Legion had a close relationship with the Americans and upon leaving, the sailors donated the Quarterdeck's large plaque in appreciation of their friendship. The American presence is still felt in Caithness as approximately ten ex-sailors have retired to live there.

The main legacies were the land, empty facilities and the housing units in Thurso. They were all handed over to the UK MoD who promptly sold them on the open market. The houses are all presently occupied and there are plans to change the use of the building at West Murkle from a storage facility into an indoor skate park, combined with an arts centre and café [13].

\subsection{Forss transmitter site}

The Forss site was abandoned and left to face the forces of the wild Scottish weather and occasional vandal, for ten years. In late 2002, New Park Highland Ltd bought nine acres of the site that contained the derelict buildings and redeveloped it into the Forss Business and Technology Park (FBTP) [14, 15]. The concept was based on creating a cluster of expertise in the nuclear decommissioning and allied industries, such as oil and gas, renewables and marine. The site's main attraction was the fact that it was only two miles from the Dounreay nuclear establishment, which aims to be recognised as the European reference site for nuclear decommissioning. The attraction for New Park was the availability of public sector grants and a deal struck with the UKAEA, which agreed to be an anchor tenant 
with a 15 year lease for around 200 of its workers that were to be decanted from Dounreay. Dounreay is now owned by the Nuclear Decommissioning Authority (NDA) and the decommissioning work is managed by Cavendish Dounreay Partnership Ltd, with Dounreay Site Restoration Ltd (DSRL), being a wholly owned subsidiary and the site licence company.

The buildings were found to be in a very poor condition and initially $£ 6.5 \mathrm{M}$ was spent in regenerating the facilities and the site's environment. New Park invested nearly $£ 5 \mathrm{M}$ and gained public sector grants of $£ 1.8 \mathrm{M}$ from Caithness and Sutherland Enterprise (CASE) and the European Regional Development Fund (ERDF) via the Scottish Highlands and Island Partnership Programme (HIPP). It met the objectives of HIPP by reducing the problems caused by peripherality and insularity and created/safeguarded employment.

New Park was committed to working in partnership with CASE, Highland Council and the local community on FBTP and other developments. They contributed to the Highlands and Islands priority of partnership working to bring more integrated and innovative approaches to community regeneration and asset management $[15,16]$.

The principle strategic objectives for Caithness are to maximise local economic benefits from nuclear decommissioning in the short to medium term, while diversifying the local economy over the long term. The development of FBTP meets these objectives as it significantly strengthens local business infrastructure and creates a centre of nuclear decommissioning expertise, which can host operators in growing technology-based sectors as the economy diversifies. FTBP objectives include;

- Creating an environment in which new firms can be started up and spun out, using incubation units

- Attracting technology firms from other sectors and working with partners to take advantage of opportunities to enable Caithness economy to diversify away from the declining nuclear sector.

The phase one refurbishment programme included $[15,16]$;

- Demolition of four buildings and removal of asbestos, fuel tanks, diesel generators and batteries, antennae, ducts, switchgear and district heating system, fire fighting system and pond

- New heating systems, thermal insulation, windows and doors

- New IT and communications cabling

- New roofs on two buildings

- New suspended ceilings, ventilation systems, toilet and kitchens

- Carpets, painting, tiling and woodwork

- New site electrical switchgear, rewiring and water services

- External buildings appearance and site landscaping

- Upgraded access road, car parks, footpaths and street lighting

- Upgraded sewerage and drainage

Phases two and three covered the renovation of buildings, creating offices, workshops, storage space and incubation units for new business starts. The Park has a high speed fibre optic information technology (IT) and telecommunications infrastructure with direct links to the Dounreay system. It has specific features 
suitable for highly sensitive government work and several buildings have a very high security rating, that are inspected by the Office of Nuclear Security. It is an open site, but is patrolled by the Civil Nuclear Constabulary based at Dounreay and also Police Scotland [15].

Tenants have come and gone and throughout the Park's lifetime over 30 companies, covering a wide range of industries, have rented/leased office and industrial space in the 13 fully serviced buildings. The site reached near full capacity in 2005 with 12 tenants supporting 250 full time equivalent jobs. The occupation levels have gone up and down over the years, due to the changing policies of the public sector organisations, the NDA and DSRL.

In its close working relationships with its tenants and public sector organisations, New Park played a role beyond that of landlord/site manager, evidenced by over 100 projects of support it has been involved in with tenants. This covered accessing finance and the provision of appropriate business skills and strategic planning. New Park, along with the NDA, created the North Highland Regeneration Fund and secured three rounds of socio economic funding for Caithness and North West Sutherland up to the value of $£ 1.5 \mathrm{M}$. This created and secured over 300 jobs locally, some of which were attracted to the area through the Forss incubation programme. In this way the company has made an important contribution to local economic development [15].

The FBTP has been successful over its 11 year life. However, there has been uncertainty generated with the owners going into administration in 2013, due to lender issues resulting from the UK financial crisis. The site currently (2014) has 12 tenants supporting around 150 jobs, plus nine people employed to manage and maintain the Park. The property services company Graham and Sibbald now manage FBTP for the administrators and has advertised it by offering a range of flexible office and industrial accommodation for lease or rent, along with a refectory and a full on-site management service. There are 13 buildings with unit space ranging from 8 to 594 sq. m (fig. 5) [17].

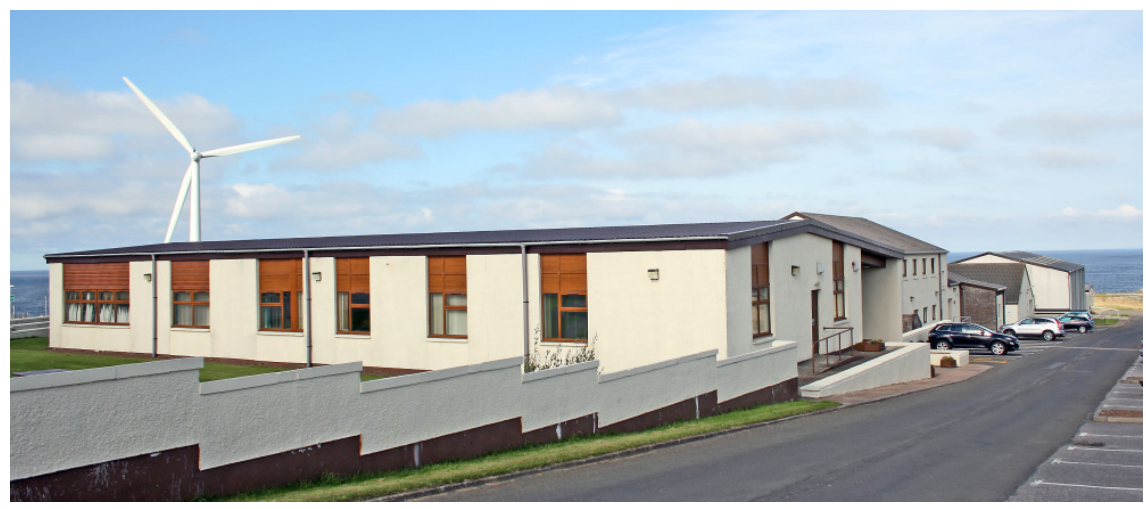

Figure 5: $\quad$ Forss Business and Technology Park office units. 9 September 2013. 
The Caithness economy has to diversify from its long term dependence on nuclear energy and both the renewables and marine energy sectors are starting to make their presence felt. Many wind farms have sprung up, including one on land at the Forss site. RES UK and Ireland Ltd built two turbines in 2003 and another four in 2007, giving a total capacity of 7.2MW (fig. 6). However, an application to build another five was rejected in 2012. The company has set up a community fund and local organisations have benefited [18]. Abbey Properties Cambridgeshire Ltd, bought part of the old site adjacent to the FBTP in November 2005 and received planning approval to develop 76 acres for a mixed use of renewable energy, offices, industrial units, warehousing and an accommodation block [14]. The company has so far failed to realise their plans.

The Royal Commission on the Ancient and Historical Monuments of Scotland, houses the national records of buildings, archaeology and industry. It has deemed the Forss site to be of significance and there is an entry with information and photographs [19].

\section{Conclusions}

The US Navy built a radio station near Thurso, Scotland, due to the Cold War and it was a great technical and social success. The sailors and their families lived in the community and enthusiastically participated in local sports, charity and social events, projecting a positive American presence. Trans-Atlantic relations were enhanced with around 100 sailors marrying local girls during the station's 30 year lifetime. Around ten sailors have retired to live in Caithness and many locals still keep in touch with ex-sailors via social media.

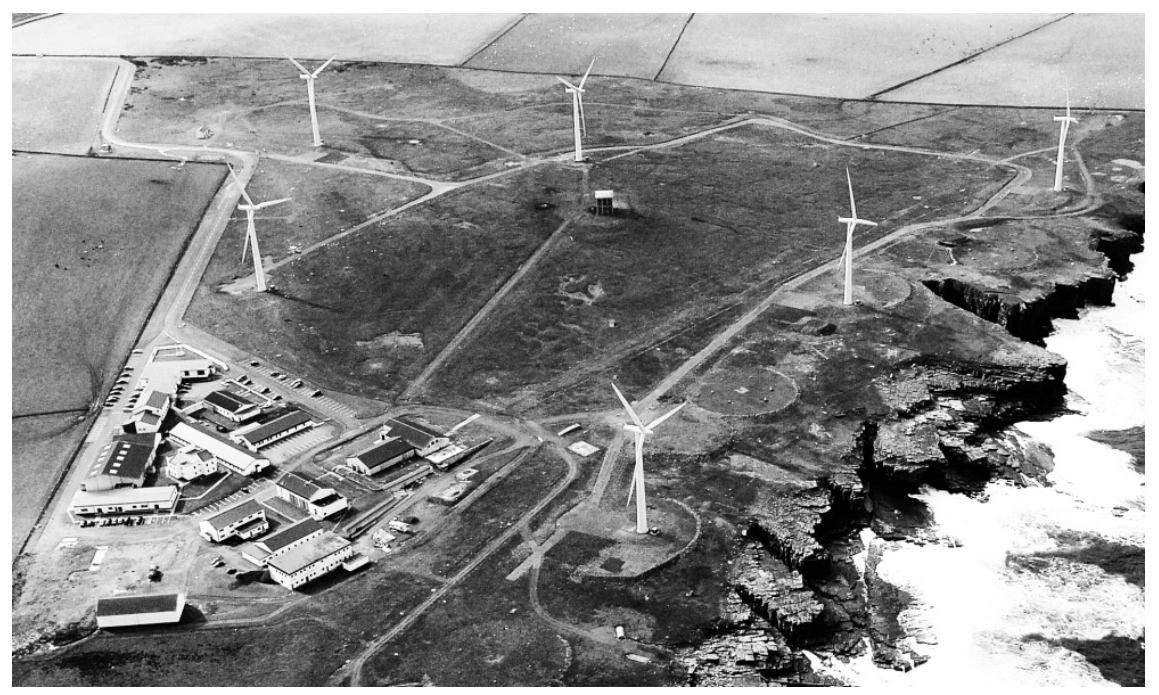

Figure 6: Aerial view of Forss Business and Technology Park. 3 September 2007. (Copyright: New Park Highland Ltd.) 
The station closed in 1992 and the local economy suffered with lost trade of around $£ 3 \mathrm{M}$ per year. However, this had no significant effect due to the socio economic influence of the Dounreay nuclear establishment.

After being abandoned for ten years, the station's transmitter site was renovated and turned into Forss Business and Technology Park through private and public sector investment. The main incentive was being so close to Dounreay and its concept is based on creating a cluster of expertise in the nuclear decommissioning and allied industries, such as oil and gas, renewables and marine. It also has a role in regenerating the socio economics of the area by encouraging the growth of small technology-based companies as the economy diversifies. The occupation levels have been over $90 \%$, but have rollercoasted due to policy changes by public sector bodies, the NDA and DSRL. The Park has been a success with a total of over 30 companies, from a wide range of sectors, leasing/renting the modern facilities and the owner, New Park Highland Ltd, has also made important contributions to local economic development.

The buildings of the ex-US defence site are all maintained in good condition and still contribute to the local economy half a century after being commissioned. With Dounreay due to be decommissioned by circa 2025, it will be interesting to see if the site can contribute to Caithness's long term objective of diversifying away from its dependence on the nuclear industry.

\section{References}

[1] John O'Groat Journal newspaper, 6 November 1992.

[2] MacGregor, J. Personal communication 14 March 2014, ex-civilian employee stationed at NAVCOMMSTA, UK.

[3] US Navy Times (Europe), 13 March 1974.

[4] Ogrodnik, S. Personal communication, 29 January 2014, ex-US Navy sailor stationed at NAVCOMMSTA, UK.

[5] US Naval Radio Station, Thurso, Scotland, Information brochure, circa 1972

[6] The Bagpiper newsletter, Volume 5 No.3, NAVCOMMSTA, UK, September 1986

[7] Woods, R., Duty in Thurso, Scotland. All Hands, February 1972.

[8] Friends of NAVCOMMSTA, UK, website, http://sac49.home.comcast.net

[9] Friends of NAVCOMMSTA, UK, Facebook page, https://www.facebook.com/\#!/groups/NAVCOMMSTATHURSO/?fref=ts

[10] US Navy radio stations, information website, http://www.navyradio.com/commsta.htm

[11] US military veterans reconnection website, http://www.vetfriends.com /units/?unit $=360824$

[12] US Forces, Thurso, tartan, Scottish Tartans Authority website, http://www.tartansauthority.com/tartan-ferret/display/5074/us-forcesthurso-military 
[13] Murkle station conversion plans, John O'Groat Journal website, 14 January 2014, http://www.johnogroat-journal.co.uk/News/Former-US-Navy-baseto-be-turned-into-skatepark-14012014.htm

[14] Forss Business and Technology Park information, Caithness community website http://www.caithness.org/atoz/forsstechnologypark/

[15] Robertson, N. Personal communication, 16 January 2014, Head of Site, Forss Business and Technology Park, By Thurso, Caithness, UK.

[16] BiGGAR Economics, Forss Business and Technology Park, Development and opportunities report, August 2005.

[17] Graham and Sibbald, property services website, http://www.gs.co.uk/Find+Property/1956/

[18] Forss Windfarm website, http://www.forss-windfarm.co.uk/

[19] Royal Commission on the Ancient and Historical Monuments of Scotland, buildings survey website, http://canmore.rcahms.gov.uk/en/site/103561 /contribution/forss+lybster+hill+us+naval+communication+unit/ 